\section{A NEW FORM OF OPHTHALMOSCOPE}

THE principal steps that have been made during the last twenty years in the knowledge of the healthy and of the diseased conditions of the eye have been effected by the employment of the ophthalmoscope, an instrument so simple, and yet so valuable, that, like other discoveries, it is only remarkable that the knowledge of the facts on which its construction depends should have so long remained unfruitful. Under all ordinary circumstances, when we look into the pupil of the eye of another person, however widely dilated it may be, it appears of an intense black hue, because the degree of illumination is insufficient to render parts so deeply seated visible, the principal portion of the light being intercepted by the head of the observer. An exceptional instance, however, is sufficiently familiar to every one, in which a brilliant reflection may be observed to occur from the back of the eye. It is that of an animal crouching in the corner of a cellar, whilst the observer is standing at the door, or looking towards a window, to which the back of the observer is turned. The principle on which the ophthalmoscope is founded is identical with this, the eye under observation being illuminated by a pencil of light proceeding, as it were, from the eye of the observer. This is accomplished by placing a steady source of light at the side of or above and somewhat behind the head of the person under observation, whilst the observer reflects its rays into the eye of the subject by means of a plane or concave mirror, the centre of which is perforated by a small opening through which he looks. The back, or fundus of the globe, then comes into view, presenting a red, or greyish red glare, the illumination being greatly increased by the use of a lens at $L$, as shown in the accompanying little

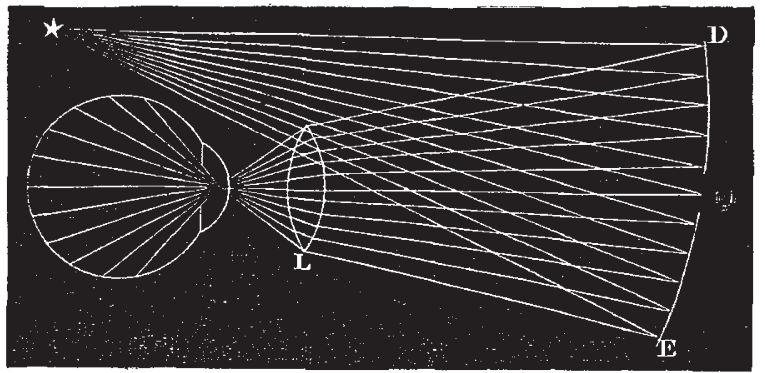

woodcut, from the recent work of Dr. Williams of Boston, where the rays of light emanating from the star are reflected from the concave mirror $\mathrm{DE}$, and rendered convergent by the lens L, lighting up the whole of the posterior surface of the globe; some of the rays returning from this pass through the opening in the mirror, and are seen by the observer at $O$. The precise mode in which the image is formed is shown in the following cut, borrowed

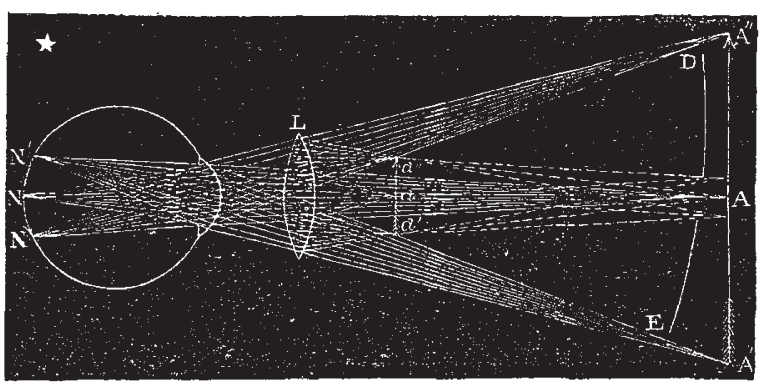

from the same work. The rays returning from $\mathrm{N}, \mathrm{N}^{\prime} \mathrm{N}^{\prime \prime}$ representing a portion of illuminated fundus, are brought to $a$ focus by the convex lens $\mathrm{L}$, at $\mathrm{A}, \mathrm{A}^{\prime} \mathrm{A}^{\prime \prime}$, and then form, the inverted aërial image of the fundus, which is seen by the observer.

The image which comes into view under these circumstances, especially if, as is usual, the pupil be dilated by the employment of a little belladonna or solution of atropine, is represented in the following woodcut, which we have carefully drawn from a child of twelve years of age. The reader must imagine the general surface to be of an orange vermilion, or scarlet vermilion tint, though in the negro it is of a very dark vermilion; the colour being produced by the reflection of the light from the capillary blood-vessels of the choroid.

In the centre is a yellowish white spot, which is the optic disc, or point of entrance of the optic nerve. This is perforated by the branches of the central artery and veins of the retina, the lighter double lines representing the arteries and the darker the veins. Above and a little to the right is a spot which is the true centre, and at the same time the most sensitive part of the eye ; from its colour it is sometimes called the macula lutea, or from its being

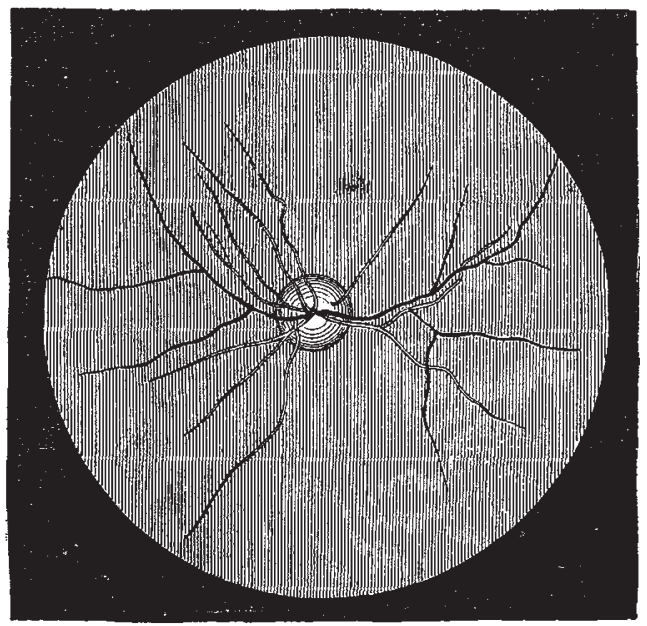

slightly depressed below the surface it is termed the fovea centralis. The changes which the optic disc, the bloodvessels, and the retina undergo in disease can of course be readily followed, and may thus enable a positive opinion to be pronounced on cases which were formerly incapable of being distinguished even by the most acute observer. Nay, it has recently been suggested by $M$. Poncet to employ it as one of the most reliable means of ascertaining that death has really taken place. A great variety of forms of the instrument have been suggested, but the ordinary hand ophthalmoscope has proved the most convenient in practice, requiring only that the room should be darkened, and that there should be some steady source of light. Dr. Beale, however, has lately suggested a form of self-illuminating ophthalmoscope, which, although by no means new in principle, is yet

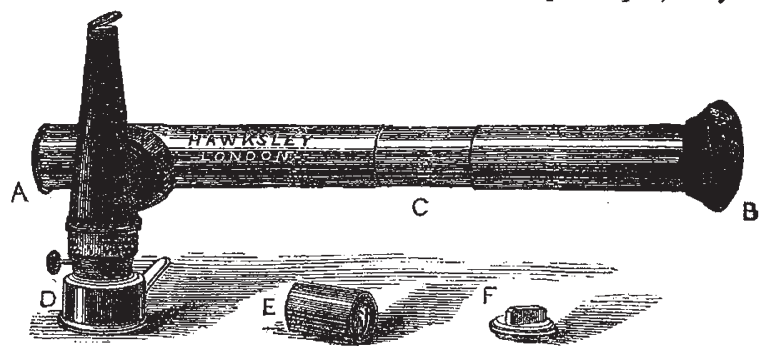

convenient in application, doing away with the necessity of a dark room, and furnishing a very steady and good light. It is represented in the preceding figure, 
and consists of a tube, A B C, of which the extremity $B$ is closely applied to the eye to be examined, thus shutting out all extraneous light. $\mathrm{D}$ is a paraffin lamp which can be easily connected or removed, the rays falling on a perforated mirror, and being reflected towards $\mathrm{B}$, a convex lens being interposed near $\mathrm{C}$, which can be approximated to or made to recede from the eye by the movement of the draw-tube $B$.

We have tried the instrument in a number of cases, and have found that while it enables a very good view of the fundus to be obtained with facility, it has the drawbacks of smelling disagreeably and also of becoming rather unpleasantly hot, from the proximity of the lamp to the eye of the observer-an inconvenience that might be remedied by placing the lateral tube at a greater distance from the end $A$.

\section{H. POWER}

\section{SCIENTIFIC SERIALS}

The Progress of Chemistry (Fahresbericht ïber die Fortschritte der Chemie und verwandter Theile anderer Wissenschaften.) Unter Mitwirkung von Th. Engelbach, Al. Naumann, W. Städel; herausgegeben von Adolph Strecker. Fïr 1868. Erstes Heft. Ausgegeben am is Februar, 1870. Giessen J. Ricker'sche Buchlandlung. 1870.

Of the 480 pages of this part, I 33 are occupied by general and physical, and 155 by inorganic chemistry, the remainder being devoted to organic chemistry.

In the first section we find an account of the method devised by Hofmann for determining the vapour densities of solids and liquids in a Torricellian vacuum, and which promises such valuable results in many cases. Tomlinson's observations on the properties of chemically clean surfaces are here noticed; and also Guthrie's experiments on the conduction of heat by liquids. A long abstract of Becquerel's papers on electro-capillary action opens the section on electro-chemical investigations, and in the division on optical chemistry Tyndall's researches on the chemical action of light find a place. Two of the chamels into which much chemical thought has been directed during the last few years are clearly indicated by the notices of numerous papers on dissociation and spectrum analysis.

In the section on inorganic chemistry we have some additional experiments in support of Frankland's theory of the cause of the light emitted by luminous flames; the combustion of hydrogen and carbonic oxide in oxygen under a pressure of ten atmospheres, and the burning of heated phosphorus vapour in hot chlorine being mentioned. Graham's researches on the occlusion of hydrogen by metals, and on the curious combination which this element forms with palladium are noticed at considerable length. The next paper to which we shall direct attention is one which at present stands amongst those on inorganic chemistry, but the compounds herein described bid fair shortly to occupy a section by themselves in a position intermediate between mineral and organic bodies; we refer to the researches of Friedel and Ladenburg on silicic oxychloride, and silicium iodoform; the study of compounds having the same constitution as well-known organic bodies, but in which silicon plays the part of carbon, promises to enable us, ultimately, to explain the constitution of that very extensive class of complex bodies containing silicon, which are found so abundantly in nature. We have a long notice of Meyer's investigations of indium and its compounds, and one on Mills's researches on the ammoniacal cobalt compounds.

Among the papers on organic chemistry, we have that of Troost and Hautenfeille, on the decomposition of mercuric cyanide at different temperatures and pressures; and the very important one by Berthelot on the synthesis of hydrocyanic acid, which he obtained by the passage of electric sparks through a mixture of acetylene and free nitrogen. A considerable space is devoted to the researches of Jungfleisch on the chlorine derivatives of benzol, and to Oppenheim's investigations of the isomeric compounds of allyl and propylene. Berthelot's valuable researches on the hydrocarbons are continued, his observations on styrol and its compounds being given. The foundation of one of the most interesting and valuable discoveries of the last few years is contained in this volume, viz., the conversion of alizarin into anthracene by its distillation from powdered zinc. Since this paper was published, its authors, Messrs. Graebe and Liebermann, have succeeded (as our readers well know) in effecting the inverse transformation, and thus producing the colouring principle of madder from one of the products of the destructive distillation of coal. We also find here the discovery of the first acetylene of the aromatic series, by Glaser in acetenylbenzol or phenylacetylene. Linnemann's preparation of normal propylalcohol and the synthesis of butylalcohol by Lieben, are noticed, as are the researches of Stenhouse on tetra- and tri-chlorochinon.

All students of chemistry will heartily welcome the appearance of the Jahresbericht, though the usefulness of the first part is much impaired for want of the index. It is very much to be regretted that this very valuable book does not appear at an earlier date; in this case the first part of the report has been published thirteen months and a half after the expiration of the year to which it refers. It must be allowed that the labour required for such a work is very arduous, but it would be a great convenience to chemists if it were possible to expedite its publication. It is reported that the Council of the Chemical Society of London intends to issue fortnightly, or monthly, short abstracts of all papers on chemistry and the allied sciences published in England and abroad. These abstracts will be made by competent chemists, and will be printed as soon as possible after the ap. pearance of the original memoirs. Such a collection of abstracts would be invaluable to many who, in consequence of their living away from London, or owing to other circumstances, have no opportunity of reading the periodicals: it would also be extremely useful to many who, though within reach of journals, have not the time to devote to the perusal of the very numerons papers published at the present time. All chemists, and many others taking a general interest in science, must wish every success to the efforts of the Council of the Chemical Society, though it is to be feared that such a journal would scarcely, at present at least, prove a commercial success.

ThE Revue des Cours Scientifiques for May 7 contains M. Blanchard's lecture before the Réunion des Sociétés Savantes, at the Sorbonne, on Scientific Work in the Departments; the continuation of Bernard's lecture on Suffocation by Charcoal fumes ; and the conclusion of M. Bouley's on Madness. In the number for May I4 we find M. Kuhne's lecture on the Science of Life, delivered on the occasion of the inauguration of the Physiological Laboratory at the University of Amsterdam; a paper by M. L. Fournier on the Ergot of Rye, being the first of a series on the parasites of cereals ; and a continuation of M. Bernard's paper.

THE American Entomologist and Botanist for April contains several good articles. A paper entitled "Wheat-rust and bar. berry rust" (placed singularly in the entomological department), defends the accuracy of the statement well known to European botanists, but which appears to have been attacked in America, that the neighbourhood of barberry trees is a prolific cause of rust in wheat; the fungus which causes the latter disease, Puccinia graminis, and the fungus which produces the bright yellow spots on the leaves of the barberry, Ecidium berberidis, being, in fact, different conditions of the same plant. An article entitled "Scientific Language," justly rebukes the tendency to use long latinised words where plain English words would do just as well, and especially the coining of barbarous compound terms, derived from two or three different languages. There are also several good descriptive papers, both entomological and botanical, specially interesting to American naturalists and collectors.

\section{SOCIETIES AND ACADEMIES}

\section{LONDON}

Entomological Society, May 2.-Mr. A. R. Wallace, president, in the chair. Mr. Hewitson exhibited a collection of new and rare butterflies, from Tropical America.-Mr. Frederick Smith exhibited a collection of Hymenoptera, from Japan. Mr. McLachlan exhibited some exotic dragon-flies. - Mr. Bates exhibited several new exotic Coprida.-Mr. G. R. Crotch sent for exlibition British specimens of Trachyphlous laticollis, a beetle not previously recorded as indigenous to this country.Papers were read, on Equatorial Lepidoptera, by Mr. Hewitson; on some new Neuroptera Odonata, by Mr. McLachlan; on new Copride, by Mr. Bates; and on Australian Curculionide, by 